\title{
Biologia e patogenicidade de Prillieuxina winteriana em pomares de gravioleira na Bahia
}

\author{
Mateus Endringer Caliman ${ }^{1} \oplus$, Delmira da Costa $_{\text {Silva }}{ }^{\oplus}$, Jadergudson Pereira $^{1} \oplus$, José Luiz Bezerra ${ }^{1} \oplus$
}

${ }^{1}$ Universidade Estadual de Santa Cruz, Campus Soane Nazaré de Andrade, Rodovia Jorge Amado, Km 16, Bairro Salobrinho. CEP 45662-900. Ilhéus, Bahia, Brasil

Autor para correspondência: Mateus Caliman (mateus_caliman@hotmail.com)

Data de chegada: 12/07/2017. Aceito para publicação em: 09/07/2018.

$10.1590 / 0100-5405 / 182617$

\section{RESUMO}

Caliman, M.E.; Silva, D.C.; Pereira, J.; Bezerra, J.L. Biologia e patogenicidade de Prillieuxina winteriana em pomares de gravioleira na Bahia Summa Phytopathologica, v.47, n.1, p.27-33, 2021.

Em áreas de plantio de gravioleira (Annona muricata) em seis municípios no estado da Bahia, observou-se o morfo assexual do fungo Prillieuxina winteriana, que causa manchas foliares e queda prematura de folhas, sendo um importante patógeno para a cultura, sendo realizadas coletas de folhas infectadas para estudo além do exame de espécimes do fungo depositados no Herbário URM. A aplicação dos Postulados de Koch possibilitou a confirmação da patogenicidade dos espécimes coletados in loco de $P$. winteriana a A. muricata, sendo os testes conduzidos em casa de vegetação e campo, onde o tempo decorrido desde a infecção das folhas até a formação de estruturas reprodutivas foi de aproximadamente quatro meses. A caracterização morfológica e histopatológica foi feita com o auxílio de microscópios ótico e eletrônico. Testes histoquímicos nas folhas infetadas mostraram haver acúmulo de proteínas, de compostos fenólicos e de alcaloides nos tecidos.

Palavras-chave: Annona muricata; Leprieurina winteriana; ciclo vital; fungo biotrófico.

\section{ABSTRACT}

Caliman, M.E.; Silva, D.C.; Pereira, J.; Bezerra, J.L. Biology and pathogenicity of Prillieuxina winteriana in soursop orchards in Bahia State, Brazil. Summa Phytopathologica, v.47, n.1, p.27-33, 2021.

Areas of soursop (Annona muricata) plantation in six municipalities in the state of Bahia, Brazil, presented the asexual morph of the fungus Prillieuxina winteriana, which causes leaf spots and premature leaf fall, constituting an important pathogen for this crop; infected leaves were collected for study and examination of specimens of this fungus deposited in URM Herbarium. Koch's Postulates made it possible to confirm the pathogenicity of specimens collected in loco from $P$. winteriana to A. muricata, and tests were conducted both in a greenhouse and in the field, where the time elapsed from the infection of leaves to the formation of reproductive structures was approximately four months. Morphological and histopathological characterization was performed under optical and electronic microscopes. Histochemical tests showed accumulation of proteins, phenolic compounds and alkaloids in the tissues of infected leaves.

Keywords: Annona muricata, Leprieurina winteriana, life cycle, biotrophic fungus.

A região sul do estado da Bahia ganhou destaque na agricultura nacional e internacional, na década de 1990, após o aparecimento da Vassoura de Bruxa do Cacaueiro, causada pelo fungo Moniliophthora perniciosa (Stahel) Aime \& Phillips-Mora, que acarretou o declínio da cacauicultura na Bahia, levando muitos produtores à falência (25). Devido a este fato, houve necessidade, por parte dos produtores, em buscar novas alternativas para substituir a renda que o cacau lhes proporcionava. Deste modo, a cultura da graviola (Annona muricata L.) começou a ganhar destaque no cenário regional, por ser uma planta de clima tropical, encontrando na região condições ideais para o seu desenvolvimento $(24,35)$.

A cultura da gravioleira é bastante suscetível a doenças fúngicas, destacando-se as manchas foliares causadas por Prillieuxina winteriana (Pazschke) G. Arnaud (=Leprieurina winteriana G. Arnauld), Grovesinia piramidalis M. N. Cline e Cercospora annonae A. S Mull. $\&$ Chupp. $(5,7,20)$. Dentre estas doenças, a mancha foliar causada pelo fungo $P$. winteriana está presente nos cinco pomares visitados durante a condução deste estudo.

Prillieuxinan winteriana pertence à família Asterinaceae
(Asterinales, Ascomycota), com inúmeras espécies polífagas e cosmopolitas (16). No Brasil, destacam-se trabalhos de Batista e colaboradores com esta família (33). Trata-se de um fungo foliícola, biotrófico, considerado específico quantos aos hospedeiros. Entretanto, a interação $P$. winteriana $\mathrm{x} A$. muricata é pouco estudada, no Brasil e também em outras regiões tropicais (15).

Prillieuxina possui 80 espécies validas (3), tendo como espécie tipo $P$. winteriana $($ anamorfo $=$ Leprieurina winteriana) $(2,36)$. Pazschke em 1892 usou o binômio Asterina winteriana para designar esta espécie. Theissen (37) transferiu-a, erroneamente, para Asterinella winteriana (Pazschke) Theiss. Asterina anonicola foi estabelecida por P. Hennings (13), mas Arnaud (2) considerou-a sinônimo de $P$. winteriana. As espécies Aulographum juruanum Henn. e Asterinella puyana Petr. foram consideradas por Hofmann (14) como sinônimos de $P$. winteriana, com base no exame dos materiais tipo.

O objetivo deste trabalho foi estudar os aspectos ecológicos e biológicos de $P$. winteriana e sua interação com $A$. muricata em áreas cultivadas na Bahia, bem como detalhar a interação patógenohospedeiro por meio de técnicas de histopatologia e microscopia. 


\section{MATERIAL E MÉTODOS}

Foram feitas coletas de folhas infectadas apresentando sintomas e sinais de $P$. winteriana em áreas produtivas de graviola em alguns municípios da Bahia, considerando diferentes condições edafoclimáticas (Tabela 1) no período de janeiro a dezembro de 2014 e fevereiro de 2015. Espécimes de $P$. winteriana depositados no herbário URM também foram examinados. Para realização dos testes de inoculação foram utilizadas folhas naturalmente infectadas coletadas aleatoriamente da copa de gravioleiras em área no município de Ilhéus, Bahia $\left(14^{\circ} 75^{\prime} 54,23 \mathrm{~S}, 39^{\circ} 23^{\prime} 11,35 \mathrm{~W}\right)$. Para os estudos do patógeno, coletaram-se folhas em diferente estágio de colonização. O material coletado foi acondicionado em sacos de papel Kraft, devidamente identificado e levado para o Laboratório de Diversidade de Fungos do Centro de Pesquisas do Cacau (CEPEC), da Comissão Executiva do Plano da Lavoura Cacaueira (CEPLAC), para a caracterização morfológica em microscopia de luz. A caracterização de superfície por meio da microscopia Eletrônica de Varredura (MEV) foi feita no Centro de Microscopia Eletrônica (CME) e os estudos histopatológicos no Laboratório de Anatomia Vegetal, ambos na Universidade Estadual de Santa Cruz (UESC).

Para as análises em microscopia de luz, foram feitas raspagens e cortes manuais das estruturas fúngicas e do tecido hospedeiro e montadas em lâmina de vidro utilizando-se lactofenol + azul de algodão (22). Para observação das colônias íntegras, utilizou-se a técnica de Callan \& Carris (6), substituindo o acetato de celulose por esmalte de unha incolor de secagem rápida (Risqué Technology), seguindo-se de montagem em álcool polivinílico + ácido lático + glicerol (PVLG) (16). Para as análises micrométricas foram medidos 30 picnotírios e 30 picnotiriósporos de cada espécime. O material coletado foi depositado no Herbário CEPEC - Fungi.

Para os testes histoquímicos, fragmentos de folhas com o patógeno foram fixados em solução de Karnovsky por 48 horas e incluídos em resina (metacrilato). Após a inclusão, cortes transversais e longitudinais foram feitos em micrótomo rotativo manual (RM 2145, Leica Deerfiel ${ }^{\circledR}$, IL, USA). Os cortes obtidos foram corados com azul de toluidina $(19,30)$, dos quais foram obtidas imagens em microscópio Leica DM 2500. Foram aplicados reagentes específicos, com seus devidos controles, na folha sem infecção (testemunha) e infectadas por $P$. winteriana para localização das principais classes de compostos químicos nos tecidos foliares (Tabela 2).

Aplicou-se a metodologia de Silveira (34) para obtenção das imagens em MEV.

Para os testes de patogenicidade, utilizou-se inoculo consistindo de picnotírios e picnotiriósporos obtidos através de raspagem de colônias fúngicas presentes em 10 folhas, os quais foram colocados em $10 \mathrm{~mL}$ de água destilada estéril. Cinco mudas de gravioleira foram pulverizadas com o inóculo do patógeno e cinco apenas com água destilada estéril (controle) até o ponto de escorrimento, sendo posteriormente cobertas com sacos plásticos umedecidos e mantidas por 72 horas em casa de vegetação na temperatura de $25 \pm 3{ }^{\circ} \mathrm{C}$, no regime natural de luz/escuro (Figura 1A-B).

Foram inoculadas, em condições de campo, oito mudas de gravioleira plantadas com espaçamento de $3 \mathrm{~m} \times 3 \mathrm{~m}$, sendo quatro mudas inoculadas com a suspensão do fungo e quatro apenas pulverizadas com água destilada estéril (testemunha). O procedimento de inoculação foi o mesmo utilizado em casa de vegetação (Figura 1C)

\section{RESULTADOS E DISCUSSÃO}

As cinco áreas estudadas apresentavam manejo cultural distinto, sendo que as gravioleiras na área do município de Tancredo Neves encontravam-se em excelente condição, havendo baixa ocorrência de $P$. winteriana nos dois períodos de coletas, mas observou-se elevada incidência e severidade ocasionadas por $G$. piramidalis. $\mathrm{Na}$ área de estudo em Vitória da Conquista, observou-se folhagem reduzida, presença de outros fungos epifíticos e baixa ocorrência

Tabela 1 Datas de coleta e coordenadas geográficas dos municípios.

\begin{tabular}{|c|c|c|c|c|}
\hline Cidade & Datas & Latitude & Longitude & Altitude \\
\hline Uma & $30 / 07 / 2014$ e $09 / 02 / 2015$ & $15^{\circ} 17^{\prime} 36^{\prime \prime} \mathrm{S}$ & $39^{\circ} 04^{\prime} 31^{\prime \prime} \mathrm{W}$ & $28 \mathrm{~m}$ \\
\hline Vitoria da Conquista & $28 / 08 / 2014$ e $02 / 02 / 2015$ & $14^{\circ} 53.361^{\prime} \mathrm{S}$ & $40^{\circ} 48.031^{\prime} \mathrm{W}$ & $870 \mathrm{~m}$ \\
\hline Tancredo Neves & 25/11/2014 e 03/03/2015 & $13^{\circ} 27^{\prime} 14^{\prime \prime} \mathrm{S}$ & $39^{\circ} 25^{\prime} 15^{\prime \prime} \mathrm{W}$ & $150 \mathrm{~m}$ \\
\hline
\end{tabular}

Tabela 2 Testes histoquímicos realizados no corte transversal da folha de Annona muricata.

\begin{tabular}{cccc}
\hline Reagente utilizado & Grupo de metabólitos & Cor da reação & Referências \\
\hline Cloreto férrico III & Composto fenólico total & Verde intenso, purpura, azul a & Johansen (1940) \\
Sudan IV & Lipídios totais & Vermelho & Pearse (1972) \\
Azul brilhante de Coomassie & Proteína & Azul & Fisher (1968) \\
Sudan Black B & Lipídios & Azul a negro & Pearse (1972) \\
Reagente de Wagner & Alcaloide & Vermelho acastanhado & Furr; Mahlberg, 1981
\end{tabular}



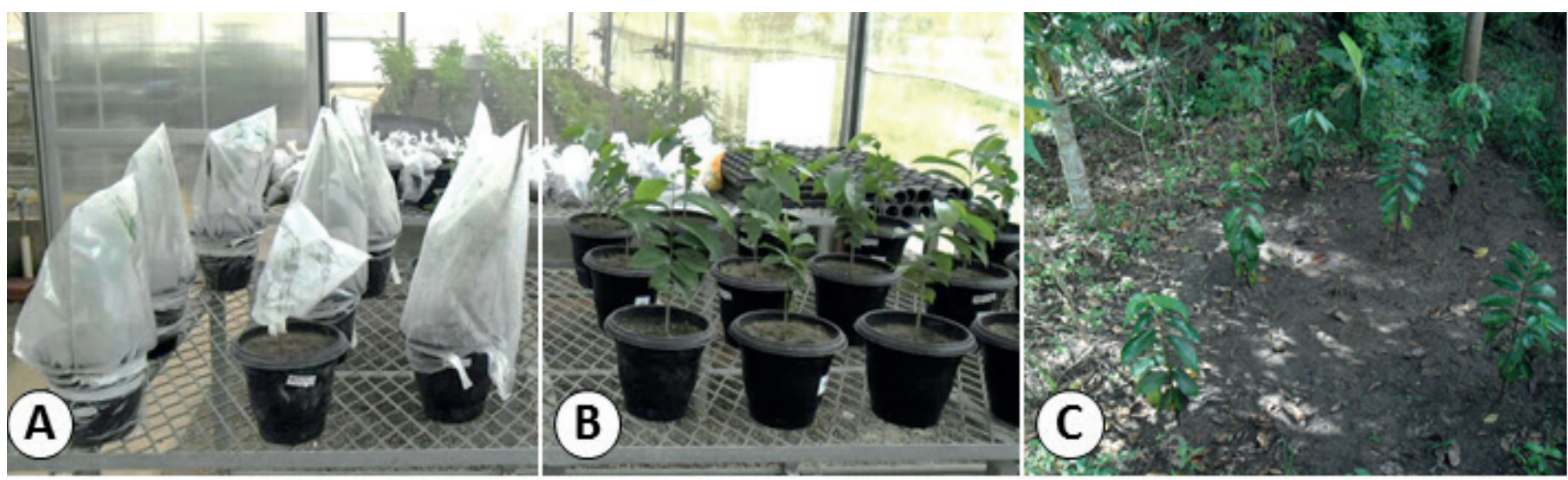

Figura 1 Testes de patogenicidade. A-B. experimento em casa de vegetação; C. experimento realizado em ambiente aberto.

de $P$. winteriana. A pouca disponibilidade de tecido susceptível e a competição com outros fungos observados nas folhas podem ter contribuído para a baixa incidência do patógeno, conforme ocorre em outros patossistemas (1). Inácio et al. (18) relatam que o número de fungos da família Asterinaceae pode ser reduzido quando há escassez de folhas disponíveis para infecção. Sabe-se que em condições de campo as plantas interagem simultaneamente com uma gama de microorganismos e também com estresses abióticos, os quais podem modificar as interações entre microorganismos $(26,31)$. A competição por substrato foliar entre fungos é conhecida (4), como demonstrado por Le May et al. (23), que verificaram que a ocorrência simultânea de dois fungos do complexo Ascochyta patogênicos à ervilha limitou a doença e afetou a reprodução destes.

As plantas existentes no pomar em Wenceslau Guimarães não foram manejadas conforme os padrões técnicos recomendados para a cultura, apresentando folhagem excessiva e alta incidência do patógeno. Junqueira et al. (21) citam que o manejo inadequado da gravioleira favorece a ocorrência de enfermidades, o que parece ter ocorrido nesta área de estudo.
Nas gravioleiras existentes no município de Una também observouse elevada incidência de $P$. winteriana nas folhas de praticamente todas as plantas. Provavelmente o ambiente mais úmido neste local e temperaturas mais elevadas, aliados à suscetibilidade do hospedeiro, favoreceram a alta severidade da doença. No local visitado em Cruz das Almas, onde as plantas de eram antigas e de porte alto, a incidência do patógeno era igualmente elevada, corroborando a afirmação de Junqueira et al. (21) de que a idade e o porte influenciam na incidência das doenças em graviola.

Nas folhas de gravioleira coletadas nos municípios referidos e nas exsicatas proveniente do URM constatou-se apenas o morfo assexual de Prillieuxina winteriana, não sendo observados ascos e ascósporos. Hofmann (14) relatou também uma maior frequência do estádio assexuado no material por ela estudado.

\section{Ciclo de vida}

O ciclo de vida do patógeno se inicia com a adesão do picnotiriósporo à superfície foliar do hospedeiro (Figura 2A). Este germina e forma um apressório, originando um peg de penetração

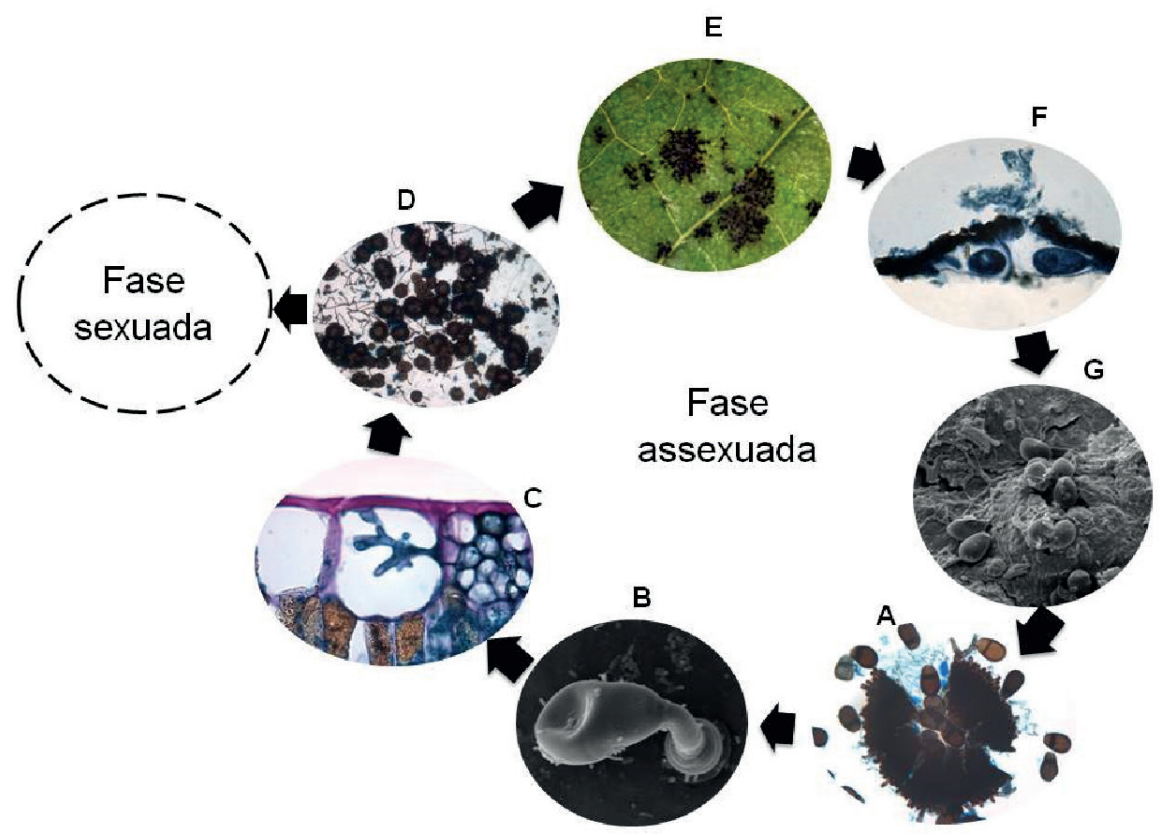

Figura 2 Ciclo de vida de Prillieuxina winteriana. A. Picnotiriósporos aderem à superfície foliar do hospedeiro. B. Picnotiriósporo haploide desenvolve um apressório que penetra na cutícula do hospedeiro. C. Colonização intracelular; D-E. Formação dos primórdios de picnotírios. F. Desenvolvimento dos picnotiriósporos. G. Liberação dos conídios maduros. 
que atravessa a cutícula do hospedeiro e forma micélio intracelular na epiderme da folha. Este micélio dará origem ao hipostroma (Figuras 2B-C). Quase ao mesmo tempo, inicia-se a formação dos primórdios de picnotírios no micélio superficial (Figuras 2D-E). Após a maturação dos picnotírios, os conídios se desenvolvem na parte interna da parede superior do conidioma (escutelo) (Figura 2F) e são liberados através de fendas estelares no escutelo, dando origem ao novo ciclo da infecção (Figura 2G). O morfo sexual, como descrito por Arnaud (2) e Hofmann (14), não foi constatado neste estudo.

\section{Teste de patogenicidade}

$\mathrm{O}$ teste de patogenicidade em mudas de gravioleira permitiu determinar o período de incubação, comparando o desenvolvimento do patógeno em casa de vegetação e em campo. No primeiro caso, após quatro meses a partir da inoculação, observou-se o surgimento de hifas superficiais e primórdios de conidiomas ao microscópio estereoscópico no aumento de 40x (Figura 3).

No teste conduzido em campo, observou-se o surgimento de micélio superficial e picnotírios após 35 dias da inoculação (Figura 4D). Os primeiros sintomas (pontos escuros na superfície foliar adaxial) apareceram cinco dias após a formação do micélio superficial (Figura 4B). Dezesseis dias após os primeiros sintomas, as folhas apresentaram alto grau de colonização e desenvolvimento dos picnotírios (Figura 4C). Após 115 dias do início da inoculação, a folha estava completamente colonizada, com picnotírios liberando picnotiriósporos. Após esta fase ocorreu o início de desfolhamento da planta. As plantas-controle não desenvolveram nenhum sintoma/ sinal do fungo, tanto em casa de vegetação quanto em campo (Figura 4A). Desta forma, foi comprovada a patogenicidade dos isolados estudados de $P$. winteriana a $A$. muricata.

A morfologia do patógeno, observada neste trabalho, confere com a descrição e ilustrações de Arnaud (2) e Hoffman (14) de $P$. winteriana sobre $A$. muricata. $\mathrm{O}$ desenvolvimento dos sintomas em campo foi maior do que em casa de vegetação, provavelmente devidos às condições climáticas mais favoráveis no primeiro caso. Os fatores ambientais, principalmente temperatura, molhamento foliar e radiação que atuam em casa de vegetação e campo são diferentes, e interferem no desenvolvimento das doenças (10).
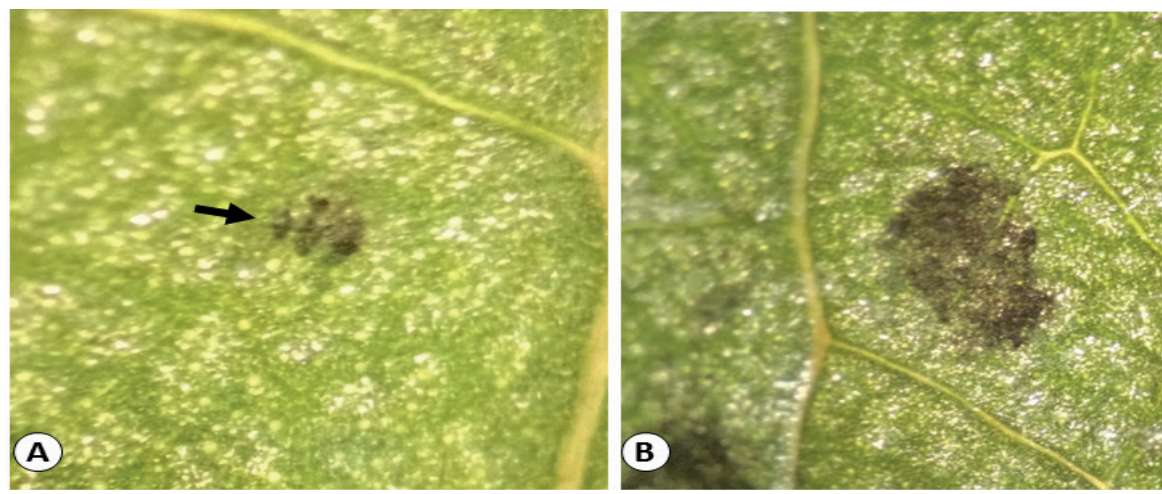

Figura 3 Experimento conduzido em casa de vegetação. A-B. surgimento de primórdios de picnotírios e hifas superficiais (seta) de Prillieuxina winteriana $(40 \mathrm{x})$.
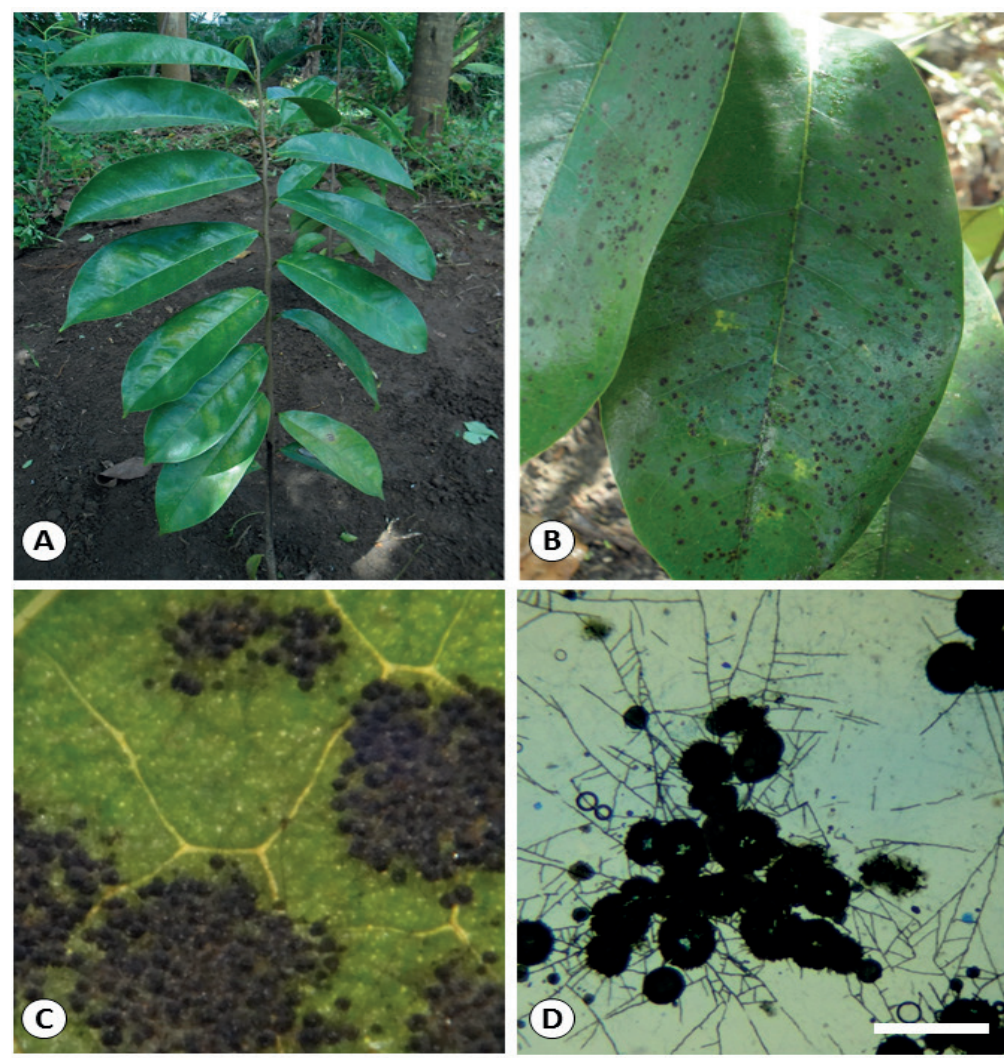

Figura 4 Sinais de Prilieuxina winteriana em folhas de Annona muricata quatro meses após a inoculação. A. Planta controle (ausência do patógeno). B. Primeiros sinais crescimento fúngico. C. Formação abundante de picnotírios. D. Micélio superficial e picnotírios. Barra: D: $200 \mu \mathrm{m}$. 
O estudo histopatológico revelou que a penetração ocorre tanto de forma direta, envolvendo a formação de apressórios (Figura 5A), como indireta, via estômatos (Figura 5B), resultando na formação de hipostroma (Figura 5D).

A colonização intracelular do patógeno (Figura 5C) ocorre de uma célula para outra colonizando, também, as células oleíferas, características da planta infectada (28), como demonstrado na Figura 5D. Hofmann (14) igualmente descreve que a penetração ocorre através das células da epiderme, seguida do preenchimento por completo das mesmas, bem como da invasão das células do parênquima paliçádico, como verificado neste estudo (Figura 5D).

$\mathrm{Na}$ análise da superfície foliar observaram-se as colônias superficiais de $P$. winteriana, com picnotírios maduros, radiados com fendas estelares por onde os picnotiriósporos são liberados. A ausência de hifopódios é uma das características do gênero Prillieuxina (Figuras $5 \mathrm{E}-\mathrm{F})(14,16)$.

\section{Análise histoquímicas}

Compostos derivados dos microorganismos podem ser reconhecidos pelas plantas, induzindo, nestas, respostas de defesa através da produção de compostos como lipídios, carboidratos e glicoproteínas, entre outros (30).

Os testes histoquímicos realizados neste estudo apresentaram reações positivas para proteínas, compostos fenólicos totais e alcaloides (32).
A presença de proteínas na região próxima à epiderme, incluindo as hifas intracelulares do fungo na epiderme, devido à reação ao reagente azul brilhante de Comassie, foi positiva indicada com coloração azul. Resultado semelhante foi observado por Conceição (8), ao analisar folhas de três espécies de Mentha.

O cloreto férrico (Figura 6B) demonstrou coloração enegrecida na região da epiderme e parênquima paliçádico, indicando reação positiva para compostos fenólicos em geral, sendo este um dos compostos predominantes observados. Compostos fenólicos também são formados em respostas à penetração de patógenos, sendo seu aparecimento considerado como parte ativa da resposta de defesa da planta $(11,12,29)$.

No teste com o reagente de Wagner para identificação de alcaloides, foram observadas reações positivas por meio de coloração castanha nas células da epiderme e do parênquima paliçádico (Figura 6A), confirmando resultados encontrados por Metcalfe \& Chalk (27) e Judd et al. (20) quanto à presença de alcaloides na família Anonnaceae. Os alcaloides presentes em espécies desta família apresentam atividade antitumoral, antimicrobiana, antioxidante e antiparasitária (9). Apesar de haver produção natural de alcaloides na planta, a resposta desta a patógenos pode potencializar a produção destes alcaloides como reação de defesa.

Este estudo contribui para o conhecimento da biologia e da patologia de $P$. winteriana sobre $A$. muricata, com possíveis consequências para o controle deste patógeno. Apesar de serem observadas áreas com alta incidência e severidade da doença, não se
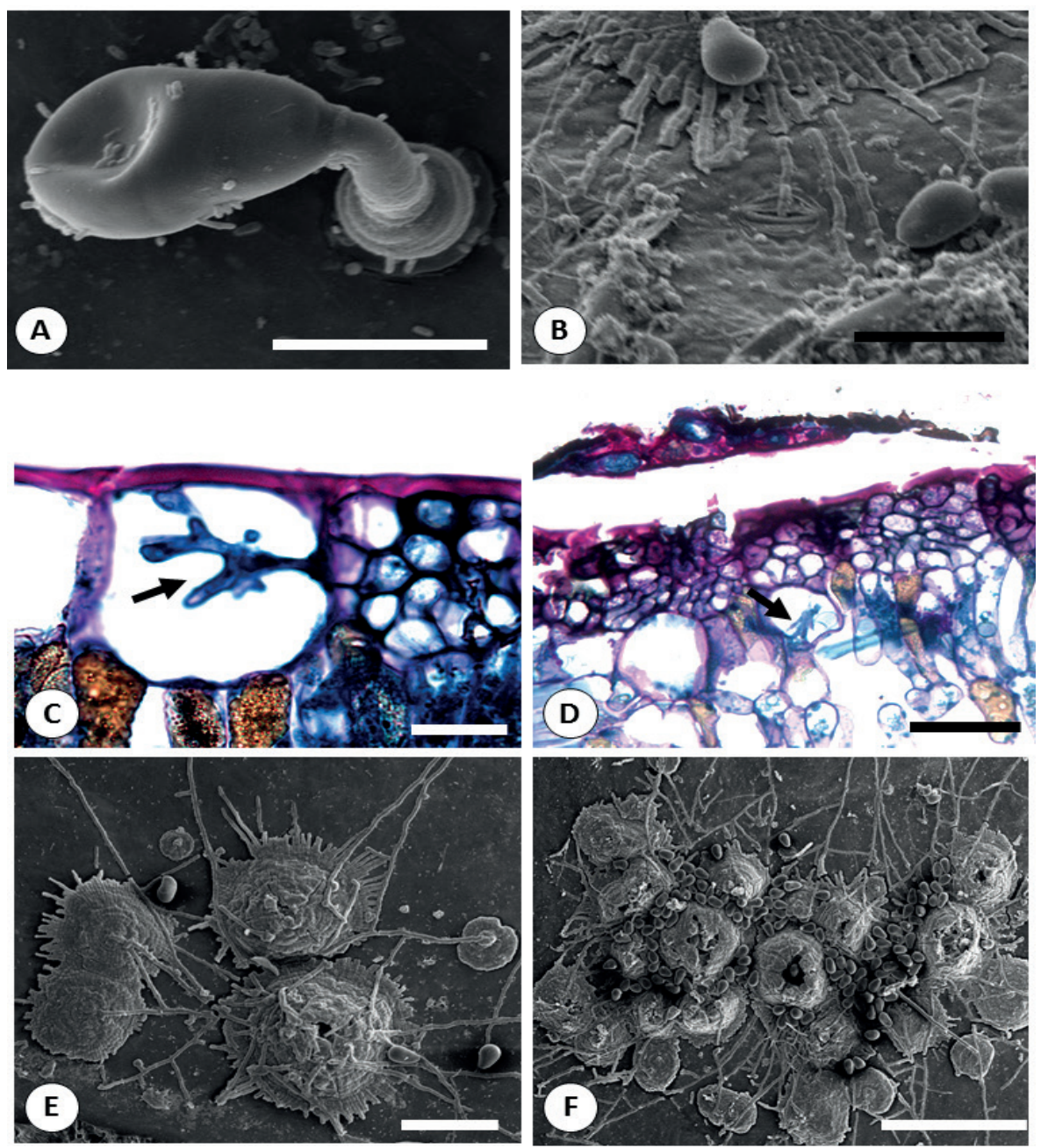

Figura 5 Penetração e colonização interna e superficial de Prillieuxina winteriana em folha de Anonna muricata. A. Eletromicrografia em MEV mostrando picnotiriósporo aderido à superfície foliar. B. Eletromicrografia em MEV evidenciando hifa originária do picnotírio penetrando no estômato (seta). C. Colonização da célula epidérmica. D. Colonização completa das células da epiderme e penetração nas células do parênquima paliçádico e da célula oleífera. E. Picnotírios imaturos e maduros. F. Picnotírios maduros liberando picnotiriósporos. Barras: A: $20 \mu \mathrm{m}$. B: $50 \mu \mathrm{m}$. C: 20 $\mu \mathrm{m}$. D: $50 \mu \mathrm{m}$. E: $100 \mu \mathrm{m}$. F: $300 \mu \mathrm{m}$. 

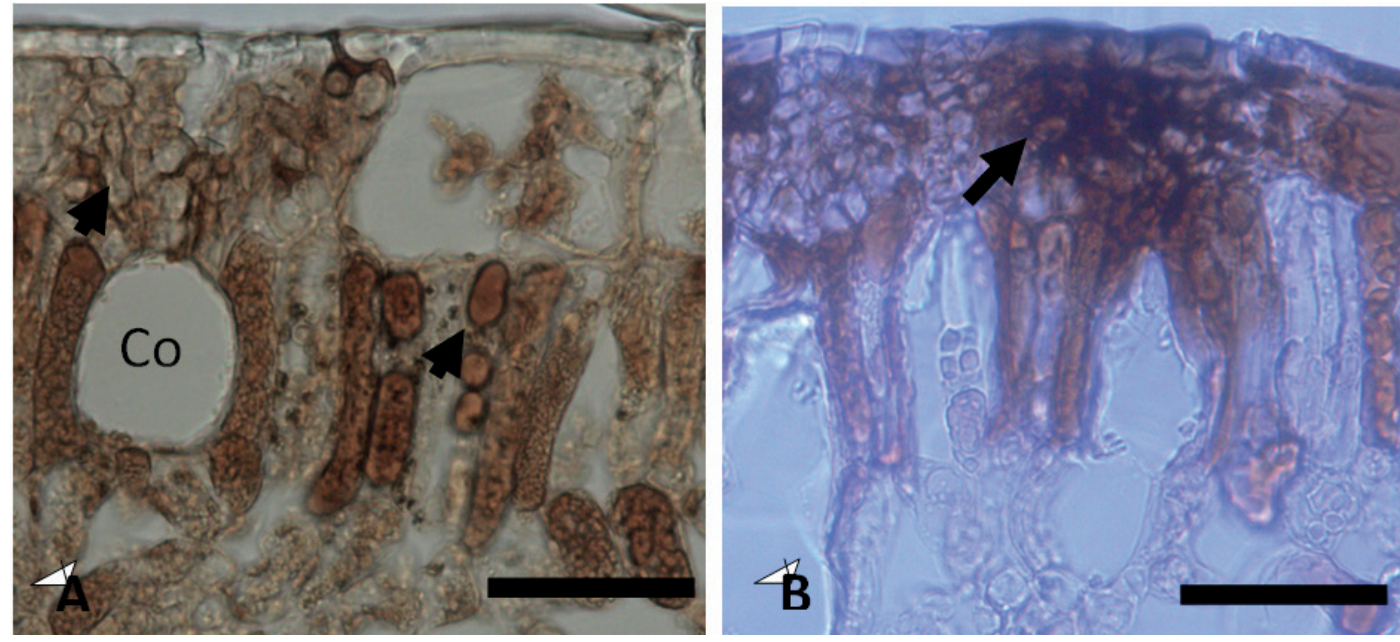

Figura 6 A. Reação com Reagente de Wagner, evidenciando alcaloides nas células epidérmicas infectadas e do parênquima paliçádico (seta). B. Reação com cloreto férrico III, evidenciando a presença de compostos fenólicos gerais nas células epidérmicas infectadas e do parênquima paliçádico (seta). Co = célula oleífera. Barra: $=50 \mu \mathrm{m}$.

verificou a presença de estruturas reprodutivas sexuadas do patógeno, sendo necessários mais estudos sobre a ecologia deste, especialmente se existem outros hospedeiros nos quais tal reprodução ocorra, além de ampliar a amostragem de plantas infectadas em áreas produtoras em outros estados brasileiros.

\section{AGRADECIMENTOS}

Os autores agradecem à UESC e à CEPLAC por disponibilizar a estrutura física e laboratorial, bem como ao Conselho Nacional de Desenvolvimento Científico e Tecnológico $(\mathrm{CNPq})$ e à Coordenação de Aperfeiçoamento de Pessoal de Nível Superior (Capes), pelo apoio financeiro. À Elizabeth Duarte e Tiago (UFRB), Armínio Santos (UESB), Leyde Nayane Nunes dos Santos Silva e Giselle Rodrigues (UESC), pelo apoio logístico e laboratorial.

\section{REFERENCIAS}

1. Amorim, L.; Rezende, J.A.M.; Bergamin filho, A. (Ed.). Manual de fitopatologia: princípios e conceitos. 4.ed. São Paulo: Agronômica Ceres, 2011. v.1, 704p.

2. Arnaud, G. Les Astérinées. Annals d’École National d'Agriculture de Montpellier. Montpellier, v.16, n.1/4, p.127, 1918.

3. Bensch, K. (cur.) MycoBank Databases: O Gênero Prillieuxina. Utrecht \& Frankfurt: 2020. Disponível em: < https://www.mycobank.org/page/ Simple\%20names\%20search $>$. Acesso em: 19 nov. 2020

4. Bettiol, W.; Morand, M.A.B. Biocontrole de doenças de plantas: uso e pespectivas. 1.ed. Jaguariúna: Embrapa Meio Ambiente, 2009. 341p.

5. Bezerra, J.L.; Luz, E.D.M.N.; Gramacho, K.P.; Figueirêdo, V.R.; Bezerra, K.M.T. Occurrence of Grovesinia pyramidalis on soursop and avocado in Brazil. Plant Pathology, Gangnamgu, v.57, p.380, 2008.

6. Callan, B.E.; Carris, L.M. Fungi on living plant substrata, including fruits. In: Mueller, G.M.; Bills, G.F.; Foster, M.S. (Ed.). Biodiversity of Fungi-Inventory and Monitoring Methods. California: Elservier Academic Press, 2004. cap.7, p.105-126.

7. Cardoso, J.E.; Martins, M.V.V.; Viana, F.M.P. Identificação e Monitoramento de Doenças na Produção Integrada da Gravioleira. Embrapa Agroindústria Tropical, Fortaleza, 23 p, $1^{\text {a }}$ edição, 2011.

8. Conceição, D.M. Caracterização histoquímica de folhas de mentas infectadas por Puccinia menthae e Erysiphe biocellata. 2009. 70f. Dis- sertação (Mestrado em Agronomia/Horticultura)-Universidade Estadual Paulista, Botucatu.

9. Costa E.V.; Pinheiro, M.L.B.; Souza, A.D.L.; Barison, A.; Campos, F.R.; Valdez, R.H.; Ueda-Nakamura, T.; Filho, B.P.D.; Nakamura, C.V. Trypanocidal Activity of Oxoaporphine and Pyrimidine- $\beta$ - Carboline Alkaloids from the Branches of Annona foetida Mart. (Annonaceae). Molecules, Basel, v.16, p.9714-9720, 2011.

10. Fiallos, F.R.G. A Ferrugem Asiática da Soja causada por Phakopsora pachyrhizi Sydow e Sydow. Ciencia y Tecnología, Guayaquil, v.4, n.2, p.45-60, 2011.

11. Fisher, D.B. Protein staining of ribboned epon sections for light microscopy. Histochemie, Berlin, v.16, n.1, p.92-96, 1968.

12. Furr, M.; Mahlberg, P.G. Histochemical analyses of laticifers and glandular trichomes in Cannabis sativa. Journal of Natural Products, Bloomington, v.44, p.153-159, 1981.

13. Hennings, P.C. Fungi S. Paulenses I. a cl. Puttemans collecti. Hedwigia, Berlin, v.41, p.104-118, 1902.

14. Hofmann, T.A. Plant parasitic Asterinaceae and Microthyriaceae from the Neotropics (Panama). 2009. 407f. Tese (Doutorado em Ciências)-The Faculty of Biological Sciences at the Johann Wolfgang Goethe - University, Frankfurt

15. Hofmann, T.A.; Piepenbring, M. Biodiversity of Asterina species on Neotropical host plants: new species and records from Panama. Mycologia, New York, v.103, n.6, p.1284-1301, 2011.

16. Hongsanan, S.; Li, Y.; Liu, J.; Hofmann, T. A.; Piepenbring, M.; Bhat, J.D.; Boonmee, S.; Doilom, M.; Singtripop, C.; Tian, Q.; Mapook, A.; Zeng X.; Bahkali, A.H.; Xu, J.; Mortimer, P.E.; Wu, X.; Yang, J.; Hyde, K.D. Revision of genera in Asterinales. Fungal Diversity, Chengdu, v.68, p.1-68, 2014.

17. Hosagoudar, V.B.; Kapoor, J.N. New technique of mounting Meliolaceous fungi. Indian Phytopathology, New Delhi, v.38 p.548-549, 1985.

18. Inácio, C.A.; Santos, D.F.; Dianese J.C. Some members of Asterinaceae (Ascomycota) from parque nacional, Brasília. In: Simpósio Nacional Cerrado, 9., 2008, Brasília. Desafios e estratégias para o equilíbrio entre sociedades, agronegócio e recursos naturais: anais, Planaltina: Embrapa Cerrados, 2008, 1 CD ROM.

19. Johansen, D. Plant Microtechnique. 1.ed. New York: McGraw Hill Book Company, 1940. 523p.

20. Judd, W.S.; Campbell, C.S.; Kellog, E.A.; Stevens, P.F.; Donogue, M.J. Sistemática vegetal: um enfoque filogenético. 3.ed. Porto Alegre: Artmed, 2009. 632p.

21. Junqueira, N.T.V.; Oliveira, M.A.S.; Ramos, V.H.V.; Pinto, A.C.Q.; Icuma, I. M. Controle de doenças da gravioleira no Cerrado. Embrapa Comunicado Técnico, Planaltina, n.31, p.1-5, 2000.

22. Kwon-Chung, K.J.; Bennett, J.E. Medical mycology. 2.ed. Malvern: Lea \& Febiger, 1992. 866p. 
23. Le May, C.; Potage, G.; Andrivon, D.; Tivoli, B.; Outreman, Y. Plant disease complex: antagonism and synergism between pathogens of the Ascochyta blight complex on pea. J Phytopathol 157:715-721 (2009) doi: 10.1111/j. 1439-0434.2009.01546.x

24. Lemos, E. E. P. A produção de anonáceas no Brasil. Revista Brasileira de Fruticultura, Jaboticabal, v.36, n. spe1, p.77-85, 2014.

25. Luz, E.D.M.N.; Bezerra, J.L.; Oliveira, M.L.; Resende, M.L.V. Doenças do cacaueiro. In: Vale, F.X.R.; Zambolim, L. Controle de doenças de planta: grandes culturas. Viçosa: Universidade Federal de Viçosa, 1997. v.1, p.611-655.

26. Maffia, L.A; Mizubuti, E.S.G. Epidemiologia de Doenças Radiculares. In: Michereff, S.J.; Andrade, D.E.G.T.; Menezes, M. Ecologia e manejo de patógenos radiculares em solos tropicais. Recife: Universidade Federal Rural de Pernambuco, 2005. cap.9, p.207-246.

27. Metcalfe, C.R.; Chalk. L. Anatomy of the Dicotyledons. 1.ed. Oxford: Clarendon Press, 1957. 806p.

28. Nicholson, R.L.; Hammerschmidt, R. Phenolic compounds and their role in disease resistance. Annual Review of Phytopathology, Palo Alto, Califórnia v.30, n.1, p.369-389, 1992.

29. Nürnberger, T.; Brunner, F. Innate immunity in plants and animals: emerging parallels between the recognition of general elicitors and pathogen-associated molecules. Current Opinion in Plant Biology, Netherlands, v.5, n. 4, p.318-324, 2002.
30. O’brien, T.P.; Feder, N.; McCully, M.E. Polycromatic staining of plant cell walls by toluidine blue. Protoplasma, Durham, v.59, p.367-373, 1964.

31. Pawlowski, M. L., Hartman, G. L. Infection mechanisms and colonization patterns of fungi associated with soybean. Pp. 25-43. In: Sadia Sultan (Eds.), Fungal Pathogenicity. IntechOpen, 2016. https://doi. org/10.5772/62305

32. Pearse, A.G.E. Histochemistry: theoretical and applied. 3.ed. Baltimore: The Williams \& Wilkins Company, 1972. v.2.

33. Silva, M.; Minter, D.W. Fungi from Brazil-Recorded by Batista and Coworkers. Mycological Papers, Devon, v.169, p.1-585, 1995.

34. Silveira, M. Preparo de amostras biológicas para microscopia eletrônica de varredura. In: Souza, W. Técnicas básicas de microscopia eletrônica aplicada às ciências biológicas. Rio de Janeiro: Sociedade Brasileira de Microscopia Eletrônica, 2011. 420p.

35. Sobrinho, R.B. Potencial de exploração de anonáceas no Nordeste do Brasil. In: Semana internacional da fruticultura, floricultura e agroindùstria, 17, 2010, Fortalez: Anais. Fortaleza: Instituto Frutal, 2010. 1 CD ROM.

36. Stevens, F.L.; Ryan, M.H. Description of Genera and Species. In: The Microthyriaceae. Urbana, The University of Illinois Press, 1939. v.17, cap.2, p.77-81. Disponível em: <https://archive.org/stream/microthyriaceae172stev\#page/76/mode/2up/search/Prillieuxina >. Acesso em: 9 jun. 2015.

37. Theissen, F. Le genre Asterinella. Brotéria Sér Botânica, Lisboa, v.10, n.2, p.101-123, 1912. 